\title{
Coastal Sea Water Quality of Nha Trang Bay, Khanh Hoa, Viet Nam
}

\author{
Vo Tran Tuan Linh, Duong Trong Kiem, Pham Hong Ngoc, Le Hung Phu, Pham Huu Tam and Le Thi Vinh \\ Department of Hydro-Geo Chemistry, Institute of Oceanography, Viet Nam Academy of Science and Technology (VAST) Viet Nam
}

\begin{abstract}
Nha Trang Bay is famous not only because of its beauty, but also of the biodiversity values, especially coral reefs. Thus, the sea water quality monitoring systems are necessary for effective and available managements to protect the ecosystems and for sustainable development. There have been several monitoring systems here but they have been done separately and unconnectedly. This research was done to take an overview and access the status and changes of water quality from 2007-2014. The data obtained rainy seasons over the years showed a quite good environment here. The environment changes were also monitored and there were some changes between seasons and over years, decreasing, increasing, or unobvious trends. However, the difference was not so much; and there was not the sign of environmental degradation in the bay from 2007 to 2014. Besides, the stoichiometric nutrients limitations were initially assessed. Since Si ratios here were always higher compared to N and P, there was not increased potential for non-diatom algal blooms. Together with the recorded nutrients concentration data, it can be said that there was no evidence of eutrophication in the bay. Although there was partial contamination of some parameters at few moments, the sea water quality of Nha Trang bay was still in a good condition (according to Vietnamese and ASEAN criteria).
\end{abstract}

Key words: Nha Trang bay, sea water quality, environmental trend, nutrients limitations.

\section{Rationale}

Nha Trang Bay, a well-known tourism site in the south of the central region, is famous not only because of its beauty, but also of the biodiversity values. However, the economic activities here have caused certain impacts to the ecosystems, especially coral reefs. The increased development of tourism in recent years creates more and more stress to the environmental quality here. Besides, thousands of cubic meters of waste water is discharged every day from residential quarters; there are five sewers through which waste water goes directly to the sea from the city, and some others to Cai river in the north (basin square around 3,000 $\mathrm{km}^{2}$, discharge around 5.6 $\mathrm{m}^{3} / \mathrm{s}$ in dry and $78 \mathrm{~m}^{3} / \mathrm{s}$ in rainy season) and Tac river in the south (basin square around $120 \mathrm{~km}^{2}$, discharge around $0.6 \mathrm{~m}^{3} / \mathrm{s}$ in dry and $2.6 \mathrm{~m}^{3} / \mathrm{s}$ in rainy season) [1]. All of these have made the Nha Trang Bay more

Corresponding author: Vo Tran Tuan Linh, M.E., research fields: environmental Engineering and Management. Email: votrantuanlinh@gmail.com. and more polluted. For these reasons, the water quality monitoring is necessary for effective and available management to protect the ecosystems here and for sustainable development. Since 1990s, monitoring programs in Nha Trang Bay are conducted regularly. The data from 2007 to 2014 [2] is quite adequate, continuous and timely to have an overview of the situation and changes in sea water quality.

The objective of this research is to assess and take an overview of status and changes of sea water quality of Nha Trang Bay.

\section{Materials and Methods}

The water samples were collected at surface and bottom layers, using $5 \mathrm{~L}$ plastic vertical water sampler at selected sites (Fig. 1); totally, 308 samples had been collected in rainy and dry seasons through 6 years 2007 and 2010-2014. The environmental basic parameters $\left(\mathrm{pH}, \mathrm{TSS}, \mathrm{DO}, \mathrm{BOD}_{5}\right)$, nutrient concentrations $\left(\mathrm{NH}_{3}, 4-\mathrm{N}, \mathrm{NO}_{3}-\mathrm{N}, \mathrm{NO}_{2}-\mathrm{N}, \mathrm{PO}_{4}-\mathrm{P}\right.$, $\mathrm{SiO}_{3}-\mathrm{Si}$ ), heavy metals ( $\mathrm{Zn}, \mathrm{Cu}, \mathrm{Pb}, \mathrm{Fe}$ ) and hydrocarbon 


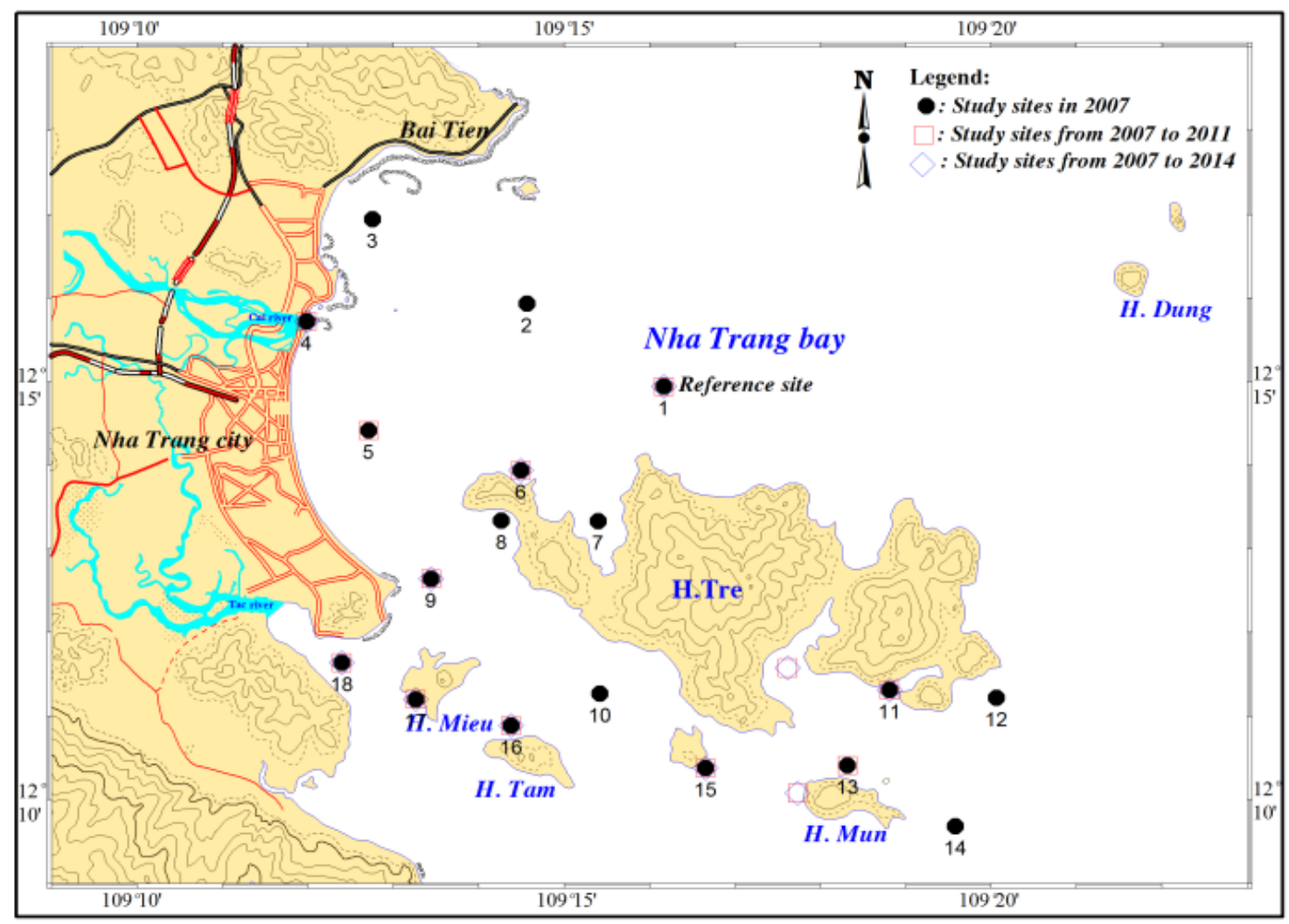

Fig. 1 Sampling locations.

were selected for statistic and comparison.

The samples were treated and analyzed following the methods in APHA [5] and FAO [6]. Vietnam National Technical Regulation on Coastal Water Quality and Asian Marine Water Quality Criteria for Aquatic Life Protection were used as references for accessing the environmental quality.

Statistic and comparison methods, using Microsoft Excel software, were applied to compare and estimate the trend of changes.

\section{Results and Discussions}

\subsection{Status of Water Quality}

\subsubsection{Water Quality in Dry Seasons}

For the basic and nutrient parameters, the data in dry seasons showed that most of values of these parameters were in the controlled level (Table 1). The high silicate concentration showed the effect of fresh water from rivers on Nha Trang bay, even in dry seasons. Especially, the Cai River had a marked effect on the northern area.

At few moments, there were partial contaminations of some nutrient parameters (TSS, $\mathrm{NH}_{3,4}-\mathrm{N}, \mathrm{NO}_{3}-\mathrm{N}$, $\left.\mathrm{PO}_{4}-\mathrm{P}\right)$. However, generally, the sea water quality in the entire bay in dry seasons was pretty good; most of the values of nutrient parameters were much lower than the standard.

For heavy metals parameters, the data from Table 2 shows that heavy metals contents were very low, except Fe. The metals such as $\mathrm{Zn}, \mathrm{Cu}$ and $\mathrm{Pb}$ had the values much lower; meanwhile Iron content was always higher than the standard. However, compared to other sea areas in Vietnam, this Fe content is not higher (even much lower than some) [7]. It might be explained that, the Iron from natural sources processes, which is major compared to the human activities sources [8,9], and the standard here is unrealistic when skipping this. 
Table 1 Values of some basic and nutrient parameters in dry season in 2014.

\begin{tabular}{lllllllllll}
\hline Areas & $\mathbf{n}$ & $\mathbf{p H}$ & $\begin{array}{l}\text { TSS } \\
(\mathrm{mg} / \mathrm{l})\end{array}$ & $\begin{array}{l}\mathbf{D O} \\
(\mathrm{mg} / \mathrm{l})\end{array}$ & $\begin{array}{l}\mathbf{B O D}_{5} \\
(\mathrm{mg} / \mathrm{l})\end{array}$ & $\begin{array}{l}\mathbf{N H}_{3,4}-\mathbf{N} \\
(\mu \mathrm{g} / \mathrm{l})\end{array}$ & $\begin{array}{l}\mathbf{N O}_{2}-\mathbf{N} \\
(\mu \mathrm{g} / \mathrm{l})\end{array}$ & $\begin{array}{l}\mathbf{N O}_{3}-\mathbf{N} \\
(\mu \mathrm{g} / \mathrm{l})\end{array}$ & $\begin{array}{l}\mathbf{P O}_{4}-\mathbf{P} \\
(\mu \mathrm{g} / \mathrm{l})\end{array}$ & $\begin{array}{l}\mathbf{S i O _ { 3 }}-\mathbf{S i} \\
(\mu \mathrm{g} / \mathrm{l})\end{array}$ \\
\hline Cairiver mouth & 2 & 7.96 & 6.76 & 1.04 & 2.0 & 8.8 & 2.7 & 39 & 7.7 & 426 \\
Tre Island & 4 & 8.03 & 6.87 & 1.09 & 1.7 & 0 & 1.8 & 33 & 10.1 & 204 \\
Tam Island & 4 & 8.12 & 6.85 & 0.87 & 2.7 & 0 & 0 & 34 & 7.1 & 196 \\
Mun Island & 8 & 8.10 & 6.75 & 1.03 & 7.4 & 4.3 & 0.6 & 34 & 7.7 & 189 \\
Tacriver mouth & 2 & 8.08 & 6.82 & 0.97 & 5.2 & 0 & 0 & 35 & 7.5 & 162 \\
Reference site & 2 & 8.03 & 6.88 & 0.99 & 2.5 & 10.8 & 3.1 & 31 & 5.7 & 375 \\
Season mean & $\mathbf{2 2}$ & $\mathbf{8 . 0 4}$ & $\mathbf{7 . 6}$ & $\mathbf{6 . 2 6}$ & $\mathbf{0 . 8 1}$ & $\mathbf{3 . 3}$ & $\mathbf{1 . 1}$ & $\mathbf{3 4}$ & $\mathbf{7 . 8}$ & $\mathbf{2 2 9}$ \\
Standard & & $\mathbf{6 . 5 - 8 . 5 *}$ & $\mathbf{5 0 *}$ & $\mathbf{2 5}$ & $\mathbf{-}$ & $\mathbf{1 0 0 *}$ & $\mathbf{5 5 * *}$ & $\mathbf{6 0} * *$ & $\mathbf{1 5} * *$ & - \\
\hline
\end{tabular}

* Vietnam National Technical Regulation on Coastal Water Quality [3].

** Asean Marine Water Quality Criteria for Aquatic Life Protection [4].

0 values mean under limit of detection.

Table 2 Values of heavy metal and hydrocarbon parameters in dry season in 2014.

\begin{tabular}{lllllll}
\hline Areas & $\mathbf{n}$ & $\begin{array}{l}\mathbf{Z n} \\
(\boldsymbol{\mu g} / \mathbf{l})\end{array}$ & $\begin{array}{l}\mathbf{C u} \\
(\boldsymbol{\mu g} / \mathbf{l})\end{array}$ & $\begin{array}{l}\mathbf{P b} \\
(\boldsymbol{\mu g} / \mathbf{l})\end{array}$ & $\begin{array}{l}\mathbf{F e} \\
(\boldsymbol{\mu g} / \mathbf{l})\end{array}$ & $\begin{array}{l}\mathbf{H C} \\
(\boldsymbol{\mu g} / \mathbf{l})\end{array}$ \\
\hline Cairiver mouth & 2 & 6.1 & 3.0 & 2.2 & 53 & 439 \\
Tre Island & 4 & 6.3 & 2.6 & 2.1 & 61 & 384 \\
Tam Island & 4 & 8.1 & 2.5 & 2.4 & 257 & 468 \\
Mun Island & 8 & 7.2 & 2.8 & 2.1 & 280 & 359 \\
Tacriver mouth & 2 & 7.9 & 2.4 & 2.1 & 256 & 497 \\
Reference site & 2 & 6.8 & 2.4 & 2.1 & 485 & 299 \\
Season mean & $\mathbf{2 2}$ & $\mathbf{7 . 1}$ & $\mathbf{2 . 6}$ & $\mathbf{2 . 1}$ & $\mathbf{2 3 2}$ & $\mathbf{3 9 8}$ \\
Standard & & $\mathbf{5 0 *}$ & $\mathbf{2}$ & - & $\mathbf{1 0 0 *}$ & $\mathbf{5 5 * *}$ \\
\hline
\end{tabular}

*Vietnam National Technical Regulation on Coastal Water Quality.

**Asean Marine Water Quality Criteria for Aquatic Life Protection.

Table 3 Values of some basic and nutrient parameters in rainy season in 2014.

\begin{tabular}{lllllllllll}
\hline Areas & $\mathbf{n}$ & $\mathbf{p H}$ & $\begin{array}{l}\mathbf{T S S} \\
(\mathrm{mg} / \mathrm{l})\end{array}$ & $\begin{array}{l}\mathbf{D O} \\
(\mathrm{mg} / \mathrm{l})\end{array}$ & $\begin{array}{l}\mathbf{B O D}_{\mathbf{5}} \\
(\mathrm{mg} / \mathrm{l})\end{array}$ & $\begin{array}{l}\mathbf{N H}_{3,4}-\mathbf{N} \\
(\mu \mathrm{g} / \mathrm{l})\end{array}$ & $\begin{array}{l}\mathbf{N O}_{2}-\mathbf{N} \\
(\mu \mathrm{g} / \mathrm{l})\end{array}$ & $\begin{array}{l}\mathbf{N O}_{3}-\mathbf{N} \\
(\mu \mathrm{g} / \mathrm{l})\end{array}$ & $\begin{array}{l}\mathbf{P O}_{4}-\mathbf{P} \\
(\mu \mathrm{g} / \mathrm{l})\end{array}$ & $\begin{array}{l}\mathbf{S i O} \mathbf{O}_{3}-\mathbf{S i} \\
(\mu \mathrm{g} / \mathrm{l})\end{array}$ \\
\hline Cairiver mouth & 2 & 7.61 & 7.16 & 3.90 & 5.2 & 14 & 0 & 41 & 7.5 & 745 \\
Tre Island & 4 & 7.74 & 6.56 & 2.09 & 3.9 & 2 & 0 & 38 & 7.6 & 272 \\
Tam Island & 4 & 8.06 & 6.87 & 1.97 & 6.6 & 5 & 0 & 35 & 7.5 & 223 \\
Mun Island & 8 & 8.09 & 6.75 & 2.30 & 5.1 & 4 & 0 & 34 & 6.7 & 211 \\
Tacriver mouth & 2 & 7.48 & 7.31 & 2.55 & 6.6 & 2 & 0 & 42 & 7.8 & 361 \\
Reference site & 2 & 7.81 & 6.68 & 1.49 & 4.6 & 0 & 0 & 34 & 7.2 & 335 \\
Season mean & $\mathbf{2 2}$ & $\mathbf{7 . 9 0}$ & $\mathbf{6 . 8}$ & $\mathbf{2 . 3 0}$ & $\mathbf{5 . 2}$ & $\mathbf{4 . 1}$ & $\mathbf{0}$ & $\mathbf{3 6}$ & $\mathbf{7 . 2}$ & $\mathbf{2 9 7}$ \\
Standard & & $\mathbf{6 . 5 - 8 . 5 *} \mathbf{5 0 *}$ & $\geq \mathbf{5}$ & - & $\mathbf{1 0 0 *}$ & $\mathbf{5 5 * *}$ & $\mathbf{6 0 * *}$ & $\mathbf{1 5 * *}$ & - \\
\hline
\end{tabular}

*Vietnam National Technical Regulation on Coastal Water Quality.

**Asean Marine Water Quality Criteria for Aquatic Life Protection.

0 values mean under limit of detection.

\subsubsection{Water Quality in Rainy Seasons}

In rainy seasons, the effect of river water was more obvious (the raw data showed that it even has effect on the reference station at some moments). There were more partial contaminations of Nitrate and Phosphate parameters. Surprisingly, there was no
Ammonia partial contamination like dry seasons. The TSS (total suspended solid) content sometimes exceeded the standard. The heavy metals parameters were in same status as dry seasons (Table 3 and 4).

Generally, although a bit worse than in dry seasons, the water quality in rainy seasons was still in the 
Table 4 Values of heavy metal and hydrocarbon parameters in rainy season in 2014.

\begin{tabular}{lllllll}
\hline Areas & $\mathbf{n}$ & $\begin{array}{l}\mathbf{Z n} \\
(\boldsymbol{\mu g} / \mathbf{l})\end{array}$ & $\begin{array}{l}\mathbf{C u} \\
(\boldsymbol{\mu g} / \mathbf{l})\end{array}$ & $\begin{array}{l}\mathbf{P b} \\
(\boldsymbol{\mu g} / \mathbf{l})\end{array}$ & $\begin{array}{l}\mathbf{F e} \\
(\boldsymbol{\mu g} / \mathbf{l})\end{array}$ & $\begin{array}{l}\text { HC } \\
(\boldsymbol{\mu g} / \mathbf{l})\end{array}$ \\
\hline Cairiver mouth & 2 & 6.1 & 3.0 & 2.2 & 53 & 439 \\
Tre Island & 4 & 6.3 & 2.6 & 2.1 & 61 & 384 \\
Tam Island & 4 & 8.1 & 2.5 & 2.4 & 257 & 468 \\
Mun Island & 8 & 7.2 & 2.8 & 2.1 & 280 & 359 \\
Tacriver mouth & 2 & 7.9 & 2.4 & 2.1 & 256 & 497 \\
Reference site & 2 & 6.8 & 2.4 & 2.1 & 485 & 299 \\
Season mean & $\mathbf{2 2}$ & $\mathbf{7 . 1}$ & $\mathbf{2 . 6}$ & $\mathbf{2 . 1}$ & $\mathbf{2 3 2}$ & $\mathbf{3 9 8}$ \\
Standard & & $\mathbf{5 0 *}$ & $\mathbf{2 5}$ & - & $\mathbf{1 0 0 *}$ & $\mathbf{5 5 * *}$ \\
\hline
\end{tabular}

*Vietnam National Technical Regulation on Coastal Water Quality.

**Asean Marine Water Quality Criteria for Aquatic Life Protection.
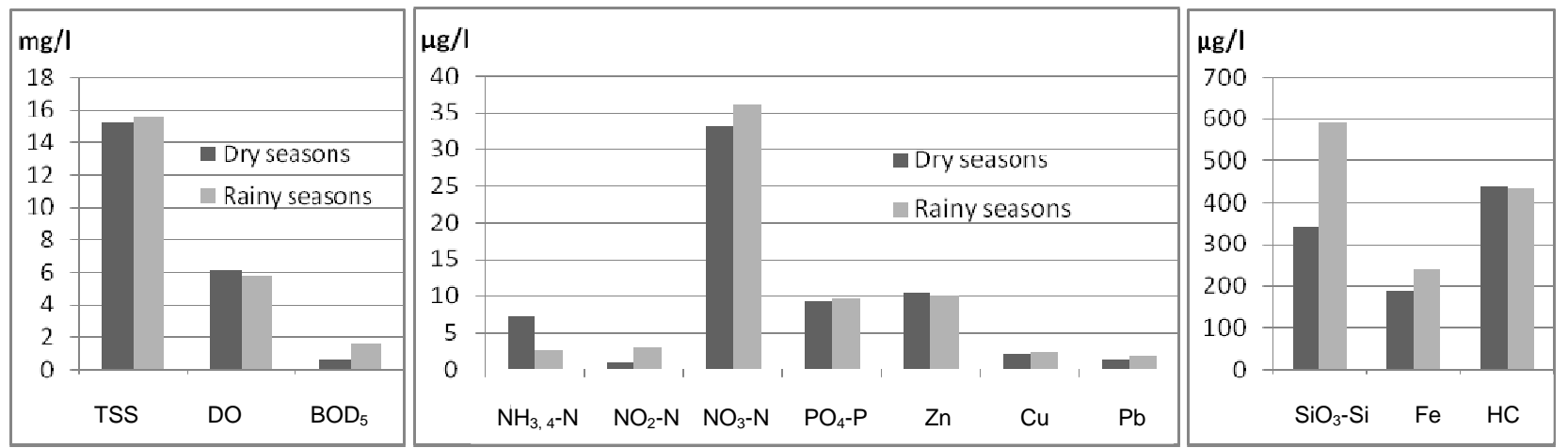

Fig. 2 Comparisons of mean values of the parameters in dry and rainy seasons from 2007 to 2014.

controlled level. However, there were some unusual notable things from the data on sea water quality:

Ammonia concentrations in the rainy season 2011 were recorded quite high, while Nitrite levels were very low compared to the same periods of 2007 and 2010;

In 11/2012, Nitrate and Phosphate concentrations were not much different to other years. However, Ammonia and Nitrite concentration were almost fully absent;

\subsubsection{Water Quality at Coral Reefs}

Beside the data of sea water quality in the entire bay above, there were two surveys taken to assess the water quality at some coral reefs in Nha Trang bay.

There was no deep difference of the values of some parameters such as $\mathrm{pH}, \mathrm{DO}$ and $\mathrm{NO}_{3}-\mathrm{N}$ between the surveys in August 2010 and August 2013. However, the TSS, $\mathrm{NH}_{3}, 4$, and $\mathrm{HC}$ parameters had changed significantly between the surveys, even the $\mathrm{NH}_{3,4}$ concentration was almost absent in 8/2013 survey.
Generally, water quality in the reef coral was good for coral reef conservation and aquatic life protection [7].

\subsection{The Changes of Water Quality in the Entire Bay}

Over the years, the values of $\mathrm{DO}, \mathrm{BOD}_{5}, \mathrm{SiO}_{3}-\mathrm{Si}$, $\mathrm{NO}_{2}-\mathrm{N}$, and Fe were higher in the rainy seasons while $\mathrm{pH}$ and NH3,4-N were lower. The comparisons are showed in Fig. 2. Similar to the environmental status in 2014, the water quality from 2007 had the situation better in rainy seasons, a bit worse in dry seasons, and in the controlled level in both.

There were some changes of the parameters in dry seasons. Some parameters such as $\mathrm{BOD}_{5}, \mathrm{Cu}$ and $\mathrm{Pb}$ had increasing trends; TSS, $\mathrm{NH}_{3,4}-\mathrm{N}$ and $\mathrm{HC}$ had been decreasing; meanwhile the others were in unobvious trends (Fig. 3). However, these changes were not significantly.

Unlike dry seasons, in rainy seasons, the changes of the parameters were in wider range. Most of the parameters changed unobviously. However, it was 
quite clear (the $R^{2}$ of graphs, 0.77 and higher) to see that five parameters $\mathrm{NO}_{2}-\mathrm{N}$, TSS, Fe and $\mathrm{HC}$ had decreasing trends, only $\mathrm{Cu}$ changed increasingly
(Fig. 4).

According to Le Thi Vinh et al. [10] and together with the data and figures above, it can be seen that
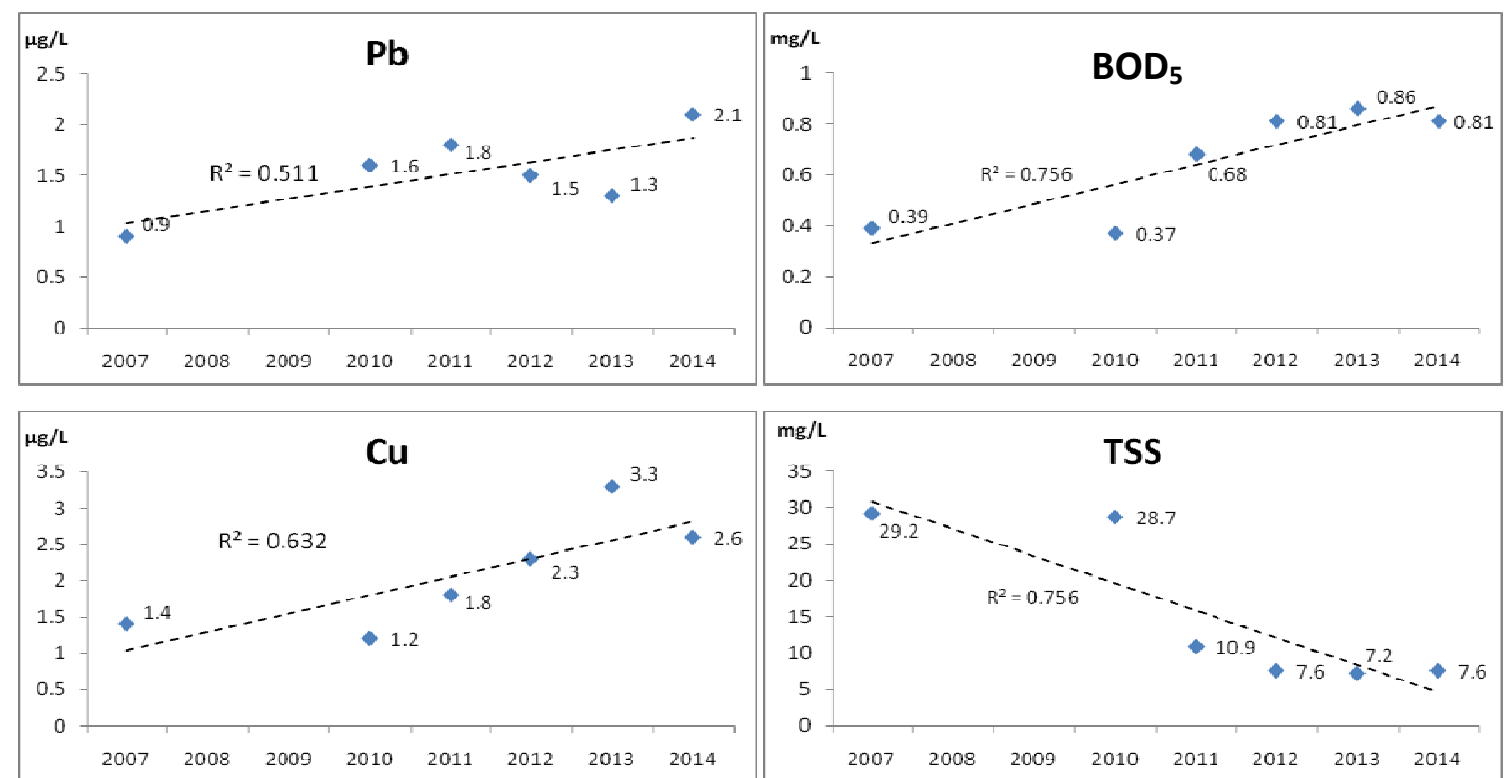

Fig. 3 Changes of some parameters in dry seasons from 2007 to 2014.
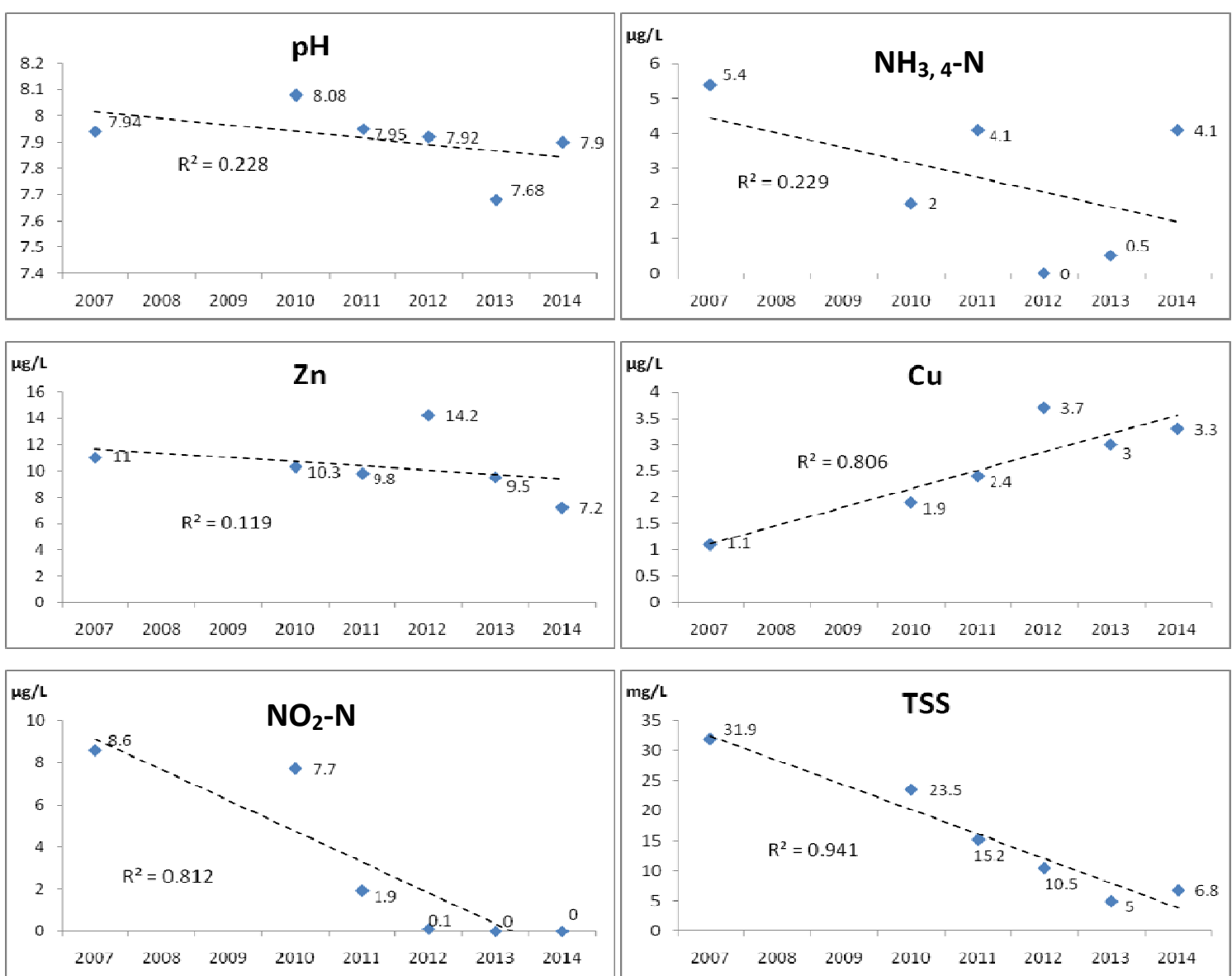

Fig. 4 Changes of some parameters in rainy seasons from 2007 to 2014. 
although there were some changes in seasons through the years, the differences were not so much. All the parameters were still in controlled level, and there was not the sign of environmental degradation in the bay till 2014.

\subsection{Nutrient Structure in the Entire Bay}

According to Dortch and Whitledge [11], the stoichiometric limitations can be assessed by calculating ambient nutrient ratios for each nutrient and applied the following criteria: $\mathrm{P}$ limitation if Si:P > 22 and DIN:P > 22; N limitation if DIN:P $<10$ and Si:DIN $>1$; Si limitation if Si:P $<10$ and Si:DIN $<1$. Therefore, through the data, most values of DIN:DIP ratios were from 6.76 to 9.97 , only the year 2007 and the dry season in 2010 had the values a bit higher than 10 , we can see a very slight $\mathrm{N}$ limitation.

Pristine rivers generally deliver $\mathrm{Si}$ to the coastal ocean in great stoichiometric excess over $\mathrm{N}$ and $\mathrm{P}$, relative to the nutrient requirements of diatoms (Si:N:P = 16:16:1) [12], and it could be assumed, through the data from table 5 , that the rivers which have effects on Nha Trang bay were still in good condition.

The data also showed that the Si:DIN and Si:DIP ratios were always higher than 3.5 and 30 , while the replete nutrient levels for diatom growth are $\mathrm{Si}: \mathrm{N} 1$ and Si:P 16. This showed that the productivity of diatoms has approached closely the upper level set by the $\mathrm{N}$ and $\mathrm{P}$ availability. Thus, it might not cause a shift in dominance from diatoms to non-siliceous forms in this area. There were several researches presented that "during periods of decreasing Si:DIP ratios, significant blooms of non-siliceous algae have increased in frequency. Often, these "novel" phytoplankton blooms included noxious and toxic forms, which replaced diatoms as the dominant biomass group [12, 13].

Table 5 Concentrations and atomic ratios of DIN, DIP and Si in the entire bay.

\begin{tabular}{|c|c|c|c|c|c|c|}
\hline Time & $\begin{array}{l}\text { DIN } \\
(\mu \mathrm{M})\end{array}$ & $\begin{array}{l}\text { DIP } \\
(\mu \mathrm{M})\end{array}$ & $\begin{array}{l}\mathbf{S i} \\
(\mu \mathrm{M})\end{array}$ & DIN:DIP & Si:DIN & Si:DIP \\
\hline $5 / 2007(n=36)$ & 3.51 & 0.42 & 12.61 & 8.4 & 3.6 & 30.0 \\
\hline $11 / 2007(n=36)$ & 3.57 & 0.36 & 25.14 & 9.9 & 7.0 & 69.8 \\
\hline Avg. 2007 & 3.54 & 0.39 & 18.88 & 9.1 & 5.3 & 48.4 \\
\hline $4 / 2010(n=26)$ & 2.98 & 0.23 & 15.46 & 13.0 & 5.2 & 67.2 \\
\hline $11 / 2010(n=26)$ & 3.69 & 0.36 & 32.50 & 10.3 & 8.8 & 90.3 \\
\hline Avg. 2010 & 3.34 & 0.30 & 23.98 & 11.1 & 7.2 & 79.9 \\
\hline $5 / 2011(n=26)$ & 2.96 & 0.26 & 14.43 & 11.4 & 4.9 & 55.5 \\
\hline $11 / 2011(n=26)$ & 2.57 & 0.38 & 19.29 & 6.8 & 7.5 & 50.8 \\
\hline Avg. 2011 & 2.77 & 0.32 & 16.86 & 8.7 & 6.1 & 52.7 \\
\hline $6 / 2012(n=22)$ & 2.92 & 0.36 & 12.68 & 8.1 & 4.3 & 35.2 \\
\hline $11 / 2012(n=22)$ & 2.51 & 0.31 & 17.46 & 8.1 & 7.0 & 56.3 \\
\hline Avg. 2012 & 2.71 & 0.34 & 15.07 & 8.0 & 5.6 & 44.3 \\
\hline $6 / 2013(n=22)$ & 2.55 & 0.27 & 9.71 & 9.4 & 3.8 & 36.0 \\
\hline $11 / 2013(n=22)$ & 2.68 & 0.25 & 21.18 & 10.7 & 7.9 & 84.7 \\
\hline Avg. 2013 & 2.61 & 0.26 & 15.45 & 10.0 & 5.9 & 59.4 \\
\hline $6 / 2014(n=22)$ & 2.74 & 0.25 & 8.18 & 11.0 & 3.0 & 32.7 \\
\hline $11 / 2014(n=22)$ & 2.86 & 0.23 & 10.61 & 12.4 & 3.7 & 46.1 \\
\hline Avg. 2014 & 2.80 & 0.24 & 9.39 & 11.7 & 3.4 & 39.1 \\
\hline P limitation & & & & $>22$ & & $>22$ \\
\hline $\mathrm{N}$ limitation & & & & $<10$ & $>1$ & \\
\hline Si limitation & & & & & $<1$ & $<10$ \\
\hline
\end{tabular}




\section{Conclusions}

Because seawater quality in entire Nha Trang Bay was strongly affected by freshwater from the rivers, although there were evidences showing that freshwater still in good condition, the riverine water quality should be also monitored thoroughly.

The water quality in rainy seasons were a bit worse than in dry seasons, but still in controlled level; although there were some partial contamination of some parameters at few moments, the seawater quality of Nha Trang Bay was still quite good in both dry and rainy seasons (according to Vietnam and Asian standard for coastal seawater quality).

There were some changes between seasons and over years, decreasing, increasing, or unobvious trends. However, these differences were not so much; there was not the sign of environmental degradation in the bay from 2007 to 2014.

It seems to support the hypothesis that Si can play an important role in coastal eutrophication [14]. Since Si ratios here were always higher compare to $\mathrm{N}$ and $\mathrm{P}$, there was not increased potential for non-diatom algal blooms. Together with the recorded nutrients concentration data, it can be said that there was no evidence of eutrophication in Nha Trang bay.

Besides, in my opinion, there are some values in the standard such as Iron, Hydrocarbon... parameters should be reconsidered, sometimes, they are quite unrealistic when we apply to assess the environment of the coastal seawater in Vietnam.

\section{Acknowledgement}

We are thankful to the DoNRE (Department of Natural Resources and Environmental) of Khanh Hoa province for allowing us to use their environmental monitoring data of Khanh Hoa's coastal areas;

Thanks to all members of the Department of Hydro-Geo Chemistry and the Management Board of Marine Protected Area of Nha Trang Bay for supporting and cooperating in our surveys;
We also thank to the projects' leaders who let us use their projects' data and specific reports as references.

\section{References}

[1] Khanh Hoa Department of Natural Resources and Environment. 2010. Report of "Environmental Situation of Khanh Hoa Province in 5 Years, from 2006 to 2010".

[2] Khanh Hoa Department of Natural Resources and Environment, 2007 to 2014; Environmental Monitoring Data of Coastal Areas.

[3] Ministry of Natural Resources and Environment 2008. National Technical Regulation on Coastal Water Quality QCVN 10/2008-BTNMT. Labor and Social Publishing House: 757-60.

[4] ASEAN Marine Water Quality Management Guidelines and Monitoring Manual 2008. Asean Marine Water Quality Criteria: 16-7.

[5] APHA. 2012. Standard Methods for Analysis of Water and Waste Water, 21st Edition.

[6] FAO. 1975. Manual of Methods in Aquatic Environment Research-Part 2: Methods for Detection, Measurement and Monitoring of water pollution.

[7] Le Thi Vinh, Duong Trong Kiem, Nguyen Hong Thu, Pham Huu Tam, Pham Hong Ngoc, Le Hung Phu and Vo Tran Tuan Linh 2012. "Environmental Quality at Coral Reefs in Nha Trang Bay.” In Proceedings of International Conference on "Bien Dong” 2012, 151-8.

[8] Kuma Kenshi 2004. "Biogeochemistry of Iron in Seawater.” Report on Amur-Okhotsk Project (2).

[9] Johnson, K. S., and Boyle E. et al. 2007. "Developing Standards for Dissolved Iron in Seawater.” Eos: Transactions, American Geophysical Union (88): 131-2.

[10] Le Thi Vinh, Nguyen Hong Thu, Duong Trong Kiem and Pham Huu Tam 2005. "Nutrient Concerntration in Nha Trang Bay in 2004.” Journal of Marine Science and Technology: 77-82.

[11] Dortch, Q., and Whitledge, T. E. 1992. "Does Nitrogen or Silicon Limit Phytoplankton Production in the Mississippi River Plume and Nearby Regions?” Continental Shelf Research (12):1293-309.

[12] Dubravko Justic, Nancy N. Rabalais, R. Eugene Turner and Quay Dortch 1994. "Changes in Nutrient Structure of River Dominated Coastal Waters: Stoichiometric Nutrient Balance and Its Consequences.” Estuarine, Coastal and Shelf Science (40): 339-56.

[13] Smayda, T. J. 1989. "Primary Production and the Global Epidemic of Phytoplankton Blooms in the Sea: A Linkage?” Novel Phytoplankton Blooms (Cosper, E. M., Bricelj, V. M. \& Carpenter, E. J., eds); Coastal and 
Estuarine Studies (35): 449-83. New York: Springer-Verlag.

[14] Smayda, T. J. 1990. "Novel and Nuisance Phytoplankton
Blooms in the Sea: Evidence for Global Epidemic.” In Toxic Marine Phytoplankton (Graneli, E., Sundstrom, B., Edler, R. \& Anderson, D. M., eds). Elsevier. 